REFERÊNCIA BIBLIOGRAFICA:

BECK, U. 1992. Risk Society. Sage, London, 1992.

\section{Os Fundamentos Teóricos do Capital Social}

Chapecó, Argos Ed. Universitária, 2005, 263 p.

Silvio Salej Higgins

\section{SÉRGIO LUÍS BOEIRA* JULIAN BORBA**}

Os Fundamentos do Capital Social, editado pela Argos, editora da UNOCHAPECÓ (argos@unichapeco. edu.br), é uma contribuição de Silvio Salej Higgins. O autor é natural de Barranquilha, Colômbia. Graduado em Filosofia pela Universidade de Javeriana (Bogotá) e mestre em Sociologia Política pela Universidade Federal de Santa Catarina (UFSC), ele atualmente é doutorando por convênio entre o Programa de Pós-Graduação em Sociologia Política (UFSC) e L'Institute de Recherche Interdisciplinaire en SócioÈconomie da Universidade de Paris IX (Dauphine). Durante uma década, Higgins trabalhou em diferentes projetos de desenvolvimento rural em seu país. Entre 1997 e 2000, foi consultor do PNUD (Colômbia) e do Centro de Investigação Popular (CINEP).

* Doutor em Ciências Humanas pela UFSC e professor na UNIVALI.

** Doutor em Ciência Política pela UFRGS e professor na UFSC.
Nessa obra, o autor tem uma postura analítica e crítica das concepções dominantes do conceito de capital social, embora também apresente uma proposta de releitura do mesmo. Sua pesquisa abrange quinze anos de produção científica sobre o tema, apoiada na base de dados "Sociological abstracts", publicada e alimentada pela Universidade de Cambridge. Os títulos com a expressão "capital social", em língua inglesa ou espanhola, somam 326 no período de 1986 a 2001.

Porém, conforme conta Higgins, mais do que uma curiosidade bibliográfica, o que o levou a problematizar o conceito de capital social foi uma experiência de trabalho num projeto de alcance regional, na Colômbia, financiado pelo Banco Mundial e executado em parceria com várias organizações da sociedade civil entre 1997 e 2000. O tema recorrente nos debates era saber se a proposta de fortalecer as redes sociais, formadas por organizações comunitárias, "tinha como meta fazê-las ganhar em eficiência econômica, ou se também deveria apontar, de forma clara, a melhoria da participação cidadã para o controle político das instituições públicas locais" (p. 27). Esta experiência serviu de base para a suspeita do autor de que o investimento em capital social, tal como o mesmo era concebido pelo Banco Mundial, impulsionava a eficiência competitiva dos empreendimentos econômicos sem, contudo, desencadear processos de redistribuição da riqueza e do poder.

Higgins parte em sua análise capítulo 1: o problema e o objeto - do seguinte pressuposto: a construção do capital social é uma "espécie de elipse com dois focos" (p. 29), um político e outro 
utilitarista ou econômico. No primeiro, distinguem-se assimetrias na obtenção de recursos por intermédio de redes de relação social; no segundo, parte-se do pressuposto de que relações de troca simétricas permitem a obtenção de recursos presentes nas estruturas de relação social. Além das diferenças, diz ele, as duas perspectivas são convergentes na idéia de que as relações sociais constituem um patrimônio "não visível", mas altamente eficaz, a serviço dos sujeitos sociais, sejam estes individuais ou coletivos. Neste sentido, "se as relações sociais estão baseadas na reciprocidade e na expectativa de cumprimento mútuo caso contrário haveria sanção social -, os motores da ação coletiva serão a confiança e a cooperação" (p. 29).

Ao tratar do foco político, o autor destaca a obra de Pierre Bourdieu, apontado como pioneiro na literatura sociológica em identificar o conceito de capital social. Bourdieu critica a teoria econômica por esta fixar-se no capital econômico convertível em dinheiro e direitos de propriedade, reduzindo o universo dos intercâmbios à troca mercantil, em que os agentes econômicos procuram a maximização de seus interesses. Como alternativa a esta redução, observa Higgins, o sociólogo francês propõe o desenvolvimento de uma ciência geral da economia prática capaz de estudar o capital, entendido como poder, incluindo o capital social e o cultural. Para ele, o capital social é um agregado de recursos atuais ou potenciais, vinculados à posse de uma rede duradoura de relações de familiaridade ou reconhecimento mais ou menos institucionalizadas. Esta abordagem foi objeto de diversas críticas: a análise do poder e da dominação em Bourdieu é considerada mecanicista, por não levar em conta a iniciativa humana, as complexas dinâmicas de criação, resistência e acomodação social. Mas, embora este autor não tenha aprofundado suas notas preliminares sobre capital social, Higgins considera que sua contribuição é relevante por tentar superar a teoria do capital presa à dicotomia econômico/nãoeconômico, bem como por seus aportes para esclarecer as relações entre cultura, redes sociais e poder.

Ao tratar do foco utilitarista ou econômico, Higgins analisa criticamente a obra do sociólogo norte-americano James Coleman, considerado um dos autores que mais contribuiu para o desenvolvimento e difusão do conceito de capital social. Na concepção de Coleman, o capital social é entendido em termos funcionais e está relacionado aos fundamentos normativos capazes de produzir integração social. Ou seja, capital social consistiria, de acordo com a síntese de Higgins, em "todos aqueles elementos de uma estrutura social que cumprem a função de servir como recursos para que atores individuais atinjam suas metas e satisfaçam seus interesses" (p. 33).

O cientista político Robert Putnam é apresentado como um "tradicionalista", cuja obra seria tributária do modelo utilitarista de Coleman. Putnam é hoje considerado a principal referência teórica na literatura sobre capital social. Higgins reconhece isso ao dedicar espaço considerável de seu trabalho à análise de suas obras. Segundo Higgins, Putnam toma como ponto de partida epistemológico o referencial colemaniano, desenvolvendo instrumentos empíricos para verificar em que medida o capital 
social pode ajudar a resolver os problemas da ação coletiva, no sentido de se obter cooperação social. Na perspectiva de Putnam, o capital social é entendido como um conjunto de características da organização social - confiança, normas e sistemas - que tornam possíveis ações coordenadas. Utilizando este conceito, desenvolve instrumentos empíricos para examinar a tese de que o capital social promove cooperação social e de que esta se reflete no desempenho das instituições. Esta tese foi testada em seu famoso livro "Making democracy work", no qual o autor, com base em um exaustivo estudo sobre a Itália, conclui que o capital social é um fator explicativo da comunidade cívica, que, por sua vez, constitui o contexto do bom desempenho institucional.

No capítulo 2, o autor aprofunda sua análise dos autores seminais e enfoques socioeconômicos. Além de Coleman, Bourdieu e Putnam, discute as idéias de Francis Fukuyama, Alejandro Portes e Mark Granovetter e examina tópicos como as fontes - altruístas ou instrumentais de capital social, as relações entre desenvolvimento e capital social, o funcionalismo sistêmico (a partir da crítica de Habermas a Parsons) e, fundamentalmente, as fronteiras entre a sociologia e economia.

No capítulo 3, Higgins examina a tradição do pensamento político e sociológico para entender as raízes que nutrem a idéia de capital social. Numa primeira parte, ela analisa o pensamento conservador e sua influência sobre Putnam, a partir de Edmund Burke e principalmente de Alexis de Tocqueville. Numa segunda parte, o autor interpreta as acepções dominantes do capital social sob duas lentes clássicas: a) o conceito funcional de integração social, tal como é desenvolvido por Durkheim e b) o conceito de ação social, de inspiração weberiana, mas ampliado pela teoria da ação comunicativa de Jürguen Habermas. $\mathrm{Na}$ última parte, o autor avalia se o conceito dominante de capital social oferece alguma inovação na forma de compreender-se a lógica coletiva e a racionalidade - e conclui que não, contrariando especialmente a teoria de Coleman. Mas não é a conclusão, e sim o exame e o cruzamento criativo dos conceitos de autores clássicos e contemporâneos, o aspecto mais relevante do capítulo.

O capítulo 4 é intitulado O capital social como mediação entre o Estado e a sociedade. Neste o autor focaliza os trabalhos de neo-institucionalistas como Peter Evans e Bo Rothstein. Por intermédio do conceito de capital social, as relações entre Estado e Sociedade têm sido (re) interpretadas, passando-se dos tradicionais modelos de "soma zero", comuns entre liberais e marxistas, para uma perspectiva de soma positiva ("ganhaganha”). Segundo Higgins, tais análises têm sido validadas por estudos empíricos em escala micro de projetos de desenvolvimento, ou na escala macro do Estado-Providência através do conceito de corporativismo. Uma das principais contribuições dessa perspectiva de análise sobre o capital social tem sido a crítica ao enfoque de Putnam segundo o qual a "comunidade cívica" é produto de uma longa tradição histórica (path dependence). Segundo o estudo de Rothstein sobre a social-democracia sueca, o capital social seria resultado principalmente de uma configuração institucional propícia à produção de confiança interpessoal. 
Ainda no capítulo 4 Higgins analisa a guinada programática de instituições como o Banco Mundial, que, de uma defesa de políticas de reformas econômicas ortodoxas nos anos oitenta, passaram a defender uma postura segundo a qual o Estado é visto de uma perspectiva "menos suspeita". Nesse contexto, tais instituições têm feito o uso constante da idéia de capital social: "o conceito de capital social ofereceria ao Banco Mundial a oportunidade de definir qual o novo influxo do Estado na economia, agora que está seduzido pelo descobrimento das novas bondades do que fora o velho demônio" (p. 216). O uso do conceito de capital social teria permitido às agências multilaterais compreender como o não econômico, o não-mercado, faz trabalhar melhor o econômico, possibilitando assim a produção de um novo consenso "mais seletivo a respeito de onde e como direcionar o rol dos fatores não-econômicos no desempenho econômico" (p. 217). Isso, segundo Higgins, permite entender o porquê da aproximação recente do Banco Mundial com setores não politizados da sociedade civil, "deixando intocadas as relações do macropoder" (idem).

Higgins finaliza o capítulo fazendo um balanço da perspectiva institucional sobre o capital social, apontando para as críticas a tal abordagem feitas pelas teorias habermasiana e marxista. Quanto à primeira, destaca o ceticismo de Habermas em relação a qualquer tipo de intervenção estatal no "mundo da vida". Assim, o que os institucionalistas estariam vendo como produção de "sinergia" entre Estado e Sociedade, o filósofo de Frankfurt interpretaria como "colonização" do mundo da vida pelo poder administrativo do Estado. Já para os marxistas, enquanto houver a propriedade privada, "o social não pode ser um adjetivo associado ao substantivo "capital'". Para Higgins, a condição para que o social seja o predicado do capital é a superação da lógica autoreferencial da acumulação pela acumulação.

Nas conclusões, o autor faz algumas sugestões de pesquisa, além da síntese das quatro grandes perspectivas sobre o conceito de capital social, a saber: a) utilitarista, na qual inclui as abordagens de Coleman e Fukuyama; b) estrutural, na qual inclui enfoques de Bourdieu, Olson e neo-institucionalistas; c) tradicionalista, na qual inclui Putnam; d) moralcomunicativa, na qual articula aspectos das obras de Durkheim e de Habermas. A análise de Higgins segue um roteiro que vai de uma forte crítica aos primeiros três enfoques, mas em sentido decrescente de contundência - com uma identificação cautelosa com aspectos das obras dos autores criticados, à exceção de Coleman - até uma abordagem cautelosamente propositiva no que se refere à articulação entre Durkheim e Habermas. Neste roteiro destaca-se a opção de Higgins por um enfoque político (e antieconomicista) a partir da retomada da obra de Bourdieu. Retomaremos este ponto mais adiante. Antes acompanharemos o autor em sua síntese das quatro perspectivas, para facilitar uma leitura comparativa.

$\mathrm{Na}$ versão dominante, classificada como utilitarista, Coleman é o alvo central da crítica. Higgins afirma que esta tem no dilema do prisioneiro um modelo e na reciprocidade estratégica a solução dominante. As normas sociais, consideradas como recurso da ação utilitária (capital social), "têm por função 
controlar, pela inibição ou pelas sanções positivas ou negativas, os comportamentos oportunistas que geram efeitos negativos sobre os demais atores" (p.249). Higgins conclui que a estratégia dominante conduz a um equilíbrio deficiente no qual ninguém colabora. Impera aqui a racionalidade instrumental.

$\mathrm{Na}$ perspectiva estrutural, predomina a ênfase na maleabilidade das regras do jogo. Mas Higgins acentua que há matizes internos nesse enfoque: em Bourdieu, a mudança das regras é decorrente do campo das lutas sociais e dos habitus adquiridos historicamente pelos atores; para Olson, a compulsoriedade é o fator limitante nos dilemas de "n" pessoas - sem ela as premissas da economia neoclássica conduzem à ruína da sociedade; os neo-institucionalistas reabilitam o conceito de burocracia eficiente de Weber "para reconhecer a margem de manobra do reformismo estatal" (p. 249).

$\mathrm{Na}$ perspectiva denominada tradicionalista, Putnam é interpretado como um autor que rejeita o hobbesianismo estrutural (força do Estado) à medida que o considera uma saída muito custosa e pouco eficiente para atingir um equilíbrio estável na sociedade. Apela à confiança, na forma de regras de reciprocidade e sistemas de participação, como solução motivacional mais relevante. Segundo a crítica de Higgins, o principal problema desta perspectiva está no fato de atribuir "pouca chance de intervenção à iniciativa das burocracias estatais (institucionalismo) na criação da confiança social" (p. 249), além de levar a pensar que o capital social é uma solução "quase misteriosa nas profundezas da história de um povo" (p. 249).
Na perspectiva moral-comunicativa, há a idéia de que pode haver discussão pública sobre interesses generalizáveis. Tal enfoque considera que levar em conta as posições dos outros só implica em superação das posições estratégicas se a ação for orientada ao "entendimento". Neste caso a motivação comunicativa é a mais importante. Esta perspectiva também assume a distinção de Durkheim entre egoísmo utilitário e individualismo moral. Isto significa, diz Higgins, que "a partir dos contratos orientados por interesses individuais não é possível derivar um sentido do dever coletivo, enquanto a autodeterminação individual vai na direção de encontrar fundamentos racionais (não-dogmáticos) para as normas sociais" (p. 249).

Ainda nas conclusões do livro, o autor destaca que, apesar de haver uma acepção instrumental que domina o uso do conceito de capital social, sua teorização ainda está apenas iniciando, carecendo ainda de uma maior sistematização e testes empíricos. Discute também as potencialidades e limitações das diferentes acepções do conceito de capital social quando examinados sob a ótica de conceitos clássicos da sociologia. Aqui parece estar presente uma das mais fortes e polêmicas teses de Higgins. Segundo sua interpretação haveria uma retro-alimentação entre a perspectiva "neoconservadora" de Putnam e "a perspectiva utilitarista e neoliberal" de Coleman. Isso ocorreria pelo fato de que tanto Putnam quanto Coleman desconfiam das "regulamentações normativas com critérios de universalidade (...) Nelas vêem a sombra ameaçadora do Estado" (p. 242). Da análise de Higgins se conclui que 
Coleman e Putnam, mesmo utilizando-se de "peças" e "engrenagens" diferenciadas em suas teorias sociais, acabam obtendo o mesmo resultado, ou seja, o apoio a um tipo de Estado neoliberal.

Uma outra questão discutida pelo autor: o conceito de capital social promove uma leitura que reduz as relações sociais a relações de mercado? Nesse ponto, utiliza-se dos desenvolvimentos recentes da sociologia econômica para afirmar que a noção de capital social, mais do que reduzir as relações sociais a relações de mercado, procura "entender como o intercâmbio econômico depende de um complexo tecido de relações humanas, onde são de vital importância os fluxos de informações, os níveis de confiança e as formas institucionais e não institucionais de controle social" (p. 242 243).

Higgins também pergunta se o conceito de capital social promove um debate entre economistas e cientistas sociais na forma como compreendem a ação coletiva. $\mathrm{Na}$ análise do autor, a teoria dominante do capital social faz parte de um renovado programa científico, que importa da microeconomia um modelo de racionalidade (instrumental) para o ator social. Nas suas palavras: "assim, quando dissemos que o capital social é um conceito em fraldas, estamos pensando que se trata de uma série de conjecturas que visam validar e, ao mesmo tempo, proteger o programa de uma socioeconomia feita sobre o patamar microeconômico" (p. 244).

$\mathrm{O}$ autor busca responder a outras duas questões mais relacionadas à dimensão político-ideológica do conceito: a primeira, se o capital social promove políticas de desenvolvimento que relegam as instituições estatais a um segundo lugar, destacando as capacidades de autogestão das organizações sociais. A segunda é sobre os economistas e as instituições multilaterais. Questiona o autor se as políticas advogadas por esses organismos promovem a eficiência (melhoria da rentabilidade) sem mexer nos problemas estruturais da redistribuição da riqueza. A resposta a estas questões aponta em sentidos diversos: por um lado, afirma que a concepção de capital social defendida pela teoria neo-institucional não estabelece a disjuntiva entre Estado e autogestão comunitária. Seu ponto de partida é o das condições institucionais de produção do capital social. Nesse sentido, suas propostas se encaminham para um "reformismo pragmático". Já a análise de Putnam é interpretada como produtora de imobilismo, pois transfere para a sociedade a responsabilidade pelo desempenho das instituições. Com relação à segunda questão afirma que a teoria dominante tem um modelo normativo de organização social fundada no individualismo e no utilitarismo.

Higgins finaliza o livro lançando alguns "elementos para um novo modelo de capital social" (p. 236), propondo a retomada do enfoque de Bourdieu, com sua perspectiva do conflito, a distinção entre poder estratégico e poder deliberativo, e a conjugação desta perspectiva do conflito com a sociologia do fato moral de Durkheim. Como anteriormente havia distinguido a perspectiva estrutural da moralcomunicativa e concentrado suas críticas nas perspectivas utilitarista e tradicionalista, o modelo proposto parece resultar numa sugestão de diálogo entre Bourdieu, Durkheim e Habermas sobre as lacunas 
das perspectivas dominantes (Coleman e Putnam).

Após esse relato do trabalho de Silvio Higgins, cabe destacar que se trata de uma obra com respeitável densidade teórica, que vai às raízes do debate político, sociológico e econômico sobre capital social, um empreendimento que consideramos de alta relevância.

Para finalizar, na tentativa de estabelecer um diálogo com o autor e ampliar o debate sobre um novo modelo de capital social, teríamos basicamente dois pontos de discordância:

a) o primeiro refere-se à aproximação Putnam/Coleman. Higgins aponta um reforço mútuo entre os autores: "Bowling alone porque rational choice" (p.239). Apesar do próprio Putnam reconhecer sua inspiração na obra de Coleman, parece-nos que a simples associação entre os dois autores sob o signo de um "modelo dominante" é mais geradora de equívocos do que de esclarecimentos. Afirmamos isso pelo fato de que, em nossa opinião, o ponto de partida epistemológico dos dois autores é diferenciado. Enquanto Coleman toma como base o modelo de indivíduo da economia neoclássica e a partir daí procura construir sua teoria social (individualismo metodológico), Putnam, por outro lado, parte da idéia holista presente na "sociologia tradicional", que advoga a impossibilidade de se estabelecer um modelo único de racionalidade para a ação social. Em outras palavras, defende o condicionamento do ator pelas estruturas sociais. No caso de Putnam, tal condicionamento é visível no papel que exercem diferentes tradições culturais nas atitudes e comportamentos políticos dos cidadãos, os quais vão refletir-se no desempenho das instituições. Ora, isso remete a uma perspectiva não teorizada por Coleman. Além do mais, ao se falar em modelos políticos normativos defendidos pelos autores verificam-se grandes disparidades entre eles: Coleman defende abertamente uma ordem política liberal, por meio da qual o Estado deve ser apenas garantidor dos contratos e liberdades naturais. Em Putnam verificase uma clara filiação à tradição do neoconservadorismo à la Tocqueville (conforme o capítulo 3), bem como à tradição do republicanismo cívico, que remonta à teoria política renascentista $\mathrm{e}$ a Maquiavel, em particular, e que tem sido retomada na teoria política contemporânea sob o título de "neorepublicanismo". Em nossa opinião, nada mais distante do liberalismo de Coleman.

b) o segundo é de ordem epistemológica mais ampla, envolvendo a relação sociedade/meio ambiente. $\mathrm{O}$ conceito de capital social, tanto em sua versão dominante (economicista), quanto em suas versões mais abertas à interdisciplinaridade (entre sociologia, economia e ciência política), ainda é um conceito fortemente antropocêntrico e sociocêntrico, que desconsidera a crise socioambiental e civilizatória em sua gênese e complexidade, e por isso ainda carece de uma abertura interdisciplinar que inclua as ciências ambientais. $O$ conceito de "capital social" subordina o de "capital físico" e, por extensão, o de "capital biofísico", desconsiderando as sociabilidades existentes em espécies nãohumanas, as complexas relações entre corpo-mente-ecossistemas e instituições humanas, além do desafio socioambiental expresso pela solidariedade diacrônica (entre as presentes e futuras gerações). 